\title{
Abrupt decrease in daylength and short-term changes in the plasma concentrations of FSH, LH and prolactin in anoestrous ewes
}

\author{
J. S. Walton*, Janet D. Evins, B. P. Fitzgerald and F. J. Cunningham \\ Department of Physiology \& Biochemistry, The University, Whiteknights, Reading RG6 $2 A J$, \\ Berkshire, U.K.
}

\begin{abstract}
Summary. The plasma concentrations of FSH, LH and prolactin in ewes were measured at frequent intervals during 24-h periods in anoestrus at different times from the onset of the breeding season. Ewes kept under natural daylength conditions were compared with ewes in which the onset of the breeding season was advanced by exposure to constant short days (8L:16D). The concentrations of FSH during mid-anoestrus did not vary during the day and there was no effect of short days or any changes which could be associated with the onset of ovulation. In all of the ewes pulsatile releases of $\mathrm{LH}$ were observed on each sampling occasion. During mid-anoestrus the occurrence of LH pulses varied between 1 and $3 /$ day and one of the pulses appeared to be synchronized with dawn. Exposure to short days did not affect the frequency of LH release. In both groups of ewes an increased frequency of LH pulses was observed in the period 12-14 days before the first ovulation but this was associated with a decrease in the magnitude of each pulse. Prolactin concentrations were raised during anoestrus and tended to be higher during the hours of darkness and in the early morning. Exposure to short days for 3 weeks abolished these diurnal changes and reduced the concentrations to non-detectable amounts.
\end{abstract}

\section{Introduction}

The seasonal pattern of reproductive activity of the ewe is largely determined by changes in daylength (Hafez, 1952). Attempts to associate changes in the concentrations of gonadotrophins in plasma with the annual changes in ovarian activity have, however, been largely inconclusive. For example, plasma concentrations of follicle-stimulating hormone (FSH) exhibit marked day-to-day fluctuations throughout anoestrus and during the breeding season but no changes which could account for the cessation or resumption of ovulation can be detected (Walton, McNeilly, McNeilly \& Cunningham, 1977). Similarly, plasma concentrations of luteinizing hormone ( $\mathrm{LH})$ do not correspond closely with the changing ovarian status (Roche, Foster, Karsch, Cook \& Dziuk, 1970; Yuthasastrakosol, Palmer \& Howland, 1975; Walton et al., 1977). In all of these experiments, however, blood was not taken at intervals frequent enough to characterize fully the pattern of hormone release; this is particularly important when measuring LH which is released in discrete pulses of short duration (Scaramuzzi \& Baird, 1977).

In contrast, changes in the plasma concentrations of prolactin can be related to breeding

* Present address: Department of Animal and Poultry Science, Ontario Agricultural College, University of Guelph, Guelph, Ontario, Canada, N1G 2W1. 
activity and have been shown to be associated with changes in daylength (Walton et al., 1977; Thimonier, Ravault \& Ortavant, 1978): values are high when the ewes are anovulatory and the days long but the levels fall markedly when daylength decreases and ovulation occurs. These changes in the release of prolactin mirror the changing sensitivity of the hypothalamus to the negative feedback action of oestradiol, which was suggested by the observation that the concentration of $\mathrm{LH}$ in the plasma of ovariectomized ewes bearing oestradiol-containing implants was high during the time of the normal breeding season and low during the time of anoestrus (Legan, Karsch \& Foster, 1977).

If hypothalamic activity is reduced during anoestrus and prolactin release is normally regulated by hypothalamic inhibition (MacLeod, 1976), then the changing pattern of prolactin release may be a useful index of hypothalamic activity in the ewe. The high levels of prolactin during anoestrus may also exert an action which is antigonadal since it has been demonstrated that the hyperprolactinaemia induced by suckling delays the resumption of ovarian activity in ewes post partum (Kann, Martinet \& Schirar, 1978). The relationship between the release of prolactin and the gonadotrophins is, therefore, of considerable importance in understanding the regulation of seasonal breeding in the ewe.

The aim of the present study was to define short-term changes in the plasma concentrations of $\mathrm{FSH}, \mathrm{LH}$ and prolactin in ewes during anoestrus and during the transition from anoestrus to breeding activity under two daylength environments.

\section{Materials and Methods}

Cross-bred ewes (25\% Finnish Landrace: 25\% Dorset Horn: 50\% Scottish Blackface) that lambed in March 1978 and had not suckled their lambs were available for the experiment. On 18 June, the ewes were weighed and randomly divided into 2 groups of 5 . One group (S) was housed in a light-proofed cabin (for details see Ducker, Thwaites \& Bowman, 1970) in which the lights were adjusted to coincide with the prevailing natural photoperiod, and the other group $(\mathrm{N})$ was housed in an open-fronted shed. A vasectomized ram equipped with a marking crayon and harness (Radford, Watson \& Wood, 1960) for the detection of oestrus was included in each group.

On 27 June, the ewes in each group were penned individually and a cannula was inserted in an external jugular vein and filled with heparin-saline solution (100 i.u./ml). From 10:00 h on 28 June until $11: 30 \mathrm{~h}$ on 29 June, blood samples $(5 \mathrm{ml})$ were withdrawn at intervals of $45 \mathrm{~min}$. Samples were taken during darkness with the aid of a dim red torch and care was taken to illuminate only the area around the end of the cannula on the back of the animal's head. Samples were immediately placed in heparinized ( 20 i.u.) tubes in ice and centrifuged within 30 min of collection at $1500 \mathrm{~g}$ for $10 \mathrm{~min}$. The plasma was separated and stored at $-20^{\circ} \mathrm{C}$ until assayed.

On 29 June the lighting schedule in the light-proof cabin was adjusted so that the ewes of Group $\mathrm{S}$ were exposed to a photoperiod of $8 \mathrm{~h}$ light (06:00-14:00 h) and $16 \mathrm{~h}$ darkness $(8 \mathrm{~L}: 16 \mathrm{D})$. This photoperiod was maintained for the rest of the experiment. Ewes in Group $\mathrm{N}$ were kept under natural daylength conditions throughout the experiment.

Blood was also obtained, using an identical protocol, from each ewe at 1, 3, 6 and 8 weeks (5 July, 19 July, 9 August and 23 August) after the change of photoperiod. Each ewe was checked daily for evidence of oestrus and additional blood samples were obtained by venepuncture twice weekly throughout the experiment. The experiment ended when all ewes had exhibited the first oestrus of the new breeding season.

Plasma concentrations of $\mathrm{FSH}, \mathrm{LH}$ and progesterone were measured using radioimmunoassays described previously (McNeilly, McNeilly, Walton \& Cunningham, 1976; Walton et al., 1977). When tested using highly purified preparations, the cross-reaction of $\mathbf{L H}$ in the assays for FSH was $0.07 \%$ and the activity of FSH in the LH assay was $0.3 \%$. Other 
pituitary hormones or plasma did not interfere in either assay. The least detectable amounts of

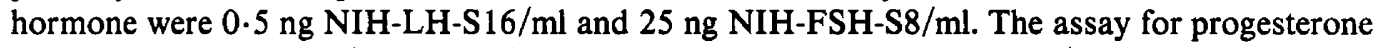
was essentially specific (Furr, 1973) and could detect $0.2 \mathrm{ng}$ progesterone $/ \mathrm{ml}$ with a recovery of $75 \%$.

Plasma concentrations of prolactin were measured using a specific, double-antibody radioimmunoassay for ovine prolactin. The antiserum was raised in rabbits against NIHprolactin-S9, which was also used as the standard in the assay. NIH-prolactin-S6 was labelled with iodine- 125 by a modification of the method described by Goldfine, Amir, Petersen \& Ingbar (1974). Prolactin $(5 \mu \mathrm{g})$ was added to a mixture of $1 \mathrm{mCi}$ sodium ${ }^{125}$ iodide (Radiochemical Centre, Amersham, U.K.) and $800 \mathrm{ng}$ chloramine T in $0.5 \mathrm{M}$-phosphate buffer, $\mathrm{pH} \mathrm{7.5}$. The total reaction volume was $50 \mu \mathrm{l}$ and the reaction was allowed to proceed for $10-15 \mathrm{~min}$. To stop the reaction, $100 \mu \mathrm{l} 0.05 \mathrm{M}$-phosphate buffer containing $2.5 \%$ bovine serum albumin and $0.005 \%$ potassium iodide were added and the iodinated prolactin was separated immediately by gel filtration on Sephadex G25. When the antiserum was used at a final dilution of $1: 105000$ the sensitivity of the assay was $3 \mathrm{ng}$ NIH-prolactin-S $9 / \mathrm{ml}$ using a protocol similar to that used for LH (Walton et al., 1977), with the exception that the labelled hormone was added on the same day as the antiserum. Cross-reactions with other hormones (NIH-FSH-S8, NIH-LH-S16, NIH-TSH-S6, NIH-GH-S10) were all $<0.01 \%$ and there were no observable non-specific effects caused by plasma.

For any hormone, all samples from each animal and from one animal per treatment were assayed together in a single assay. All estimations were carried out in duplicate and the precision of the assays, as reflected by the intra-assay coefficient of variation, was always $<10 \%$. The first ovulation of the breeding season in each case was presumed to precede the first normal luteal-phase profile of progesterone (Walton et al., 1977). A pulse of LH was defined as the incidence of a significantly elevated level followed by at least two progressively lower values which were still elevated above basal concentrations. On a small number of occasions, when the occurrence of these pulses was very frequent, this criterion could not be satisfied and a subjective assessment was made of the number of pulses occurring during the collection period. Statistical comparisons were carried out using Student's $t$ test.

\section{Results}

\section{Onset of ovulation and oestrus}

The ewes in Group N weighed $64.0 \pm 1.6$ (s.e.m.) kg and those in Group S weighed $71.6 \pm$ $1.6 \mathrm{~kg}$. The first oestrus of the breeding season was observed $91.8 \pm 0.5$ (s.e.m.) days in Group $\mathrm{N}$ ewes and $74.2 \pm 3.2$ days after the longest day in Group $\mathrm{S}$ ewes $(P<0.001$, d.f. $8, t=5.41)$. Measurements of plasma concentrations of progesterone indicated that each ewe ovulated once without exhibiting oestrus before the first overt oestrus. The estimated mean \pm s.e.m. onset of ovulation was $74.8 \pm 0.5$ days and $57.2 \pm 3.2$ days after the longest day in the ewes in Group $\mathrm{N}$ and $\mathrm{S}$ respectively.

The endocrine responses to the reduced daylength will be considered only for the first 4 weeks of the experiment because changes after this may be a reflection of the onset of ovulation rather than a response to photoperiod.

\section{$F S H$}

Mean plasma concentrations of FSH during mid-anoestrus ranged from 50 to $80 \mathrm{ng} / \mathrm{ml}$ with no significant changes occurring during the 24 - $h$ period of study (Text-fig. $1 \mathrm{a}$ ). There was a trend towards increasing concentrations in the early morning but this was not significant. The pattern 1 week and 3 weeks later was similar in both groups of ewes (Text-figs $1 \mathrm{~b}$ and $1 \mathrm{c}$ ). 


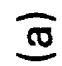

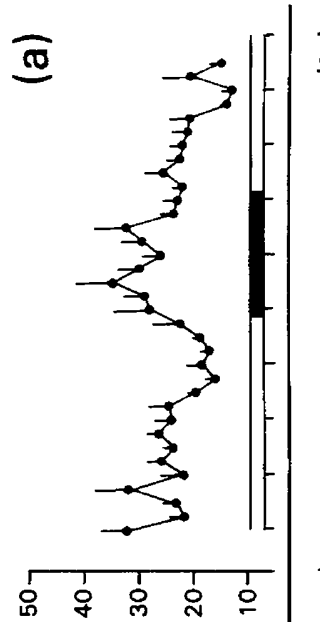

(Iw/6u) u!20ejodd

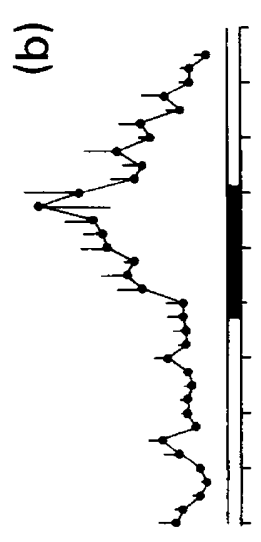

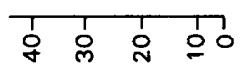
(ןس/6u) u!poejosd
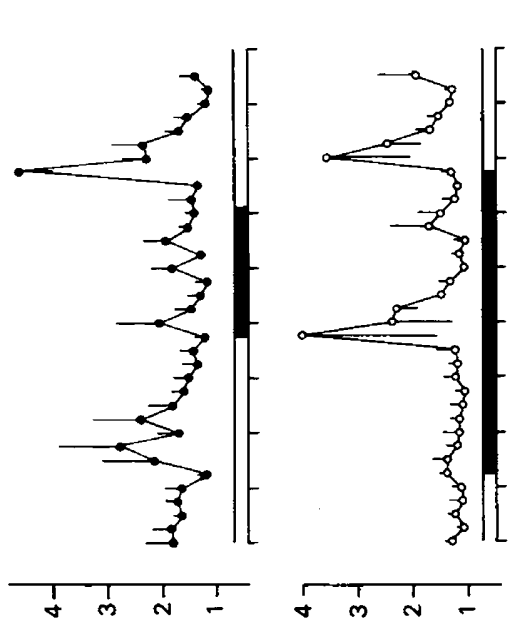

(Iw/6u) Hา

(fய/6u) $\mathrm{H}$ ר


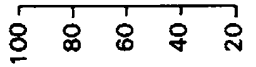

(IW/6u) HSJ

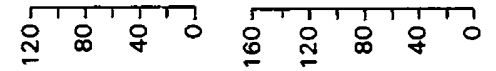
(jw/6u) HSJ

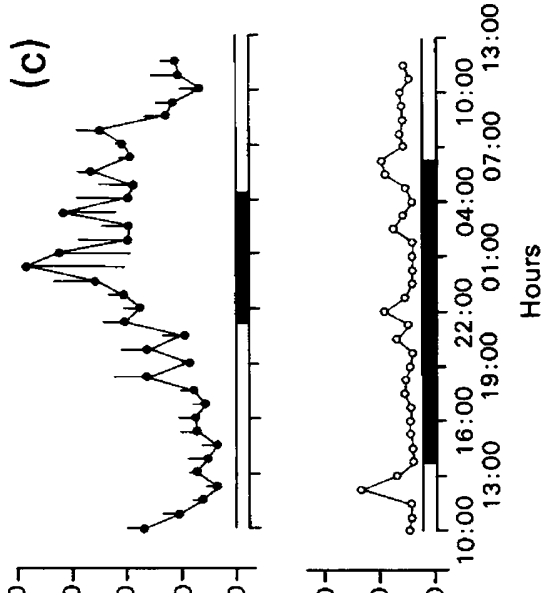

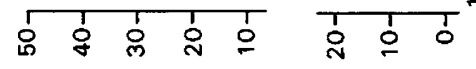
(ाய/6u) u!ıojodd

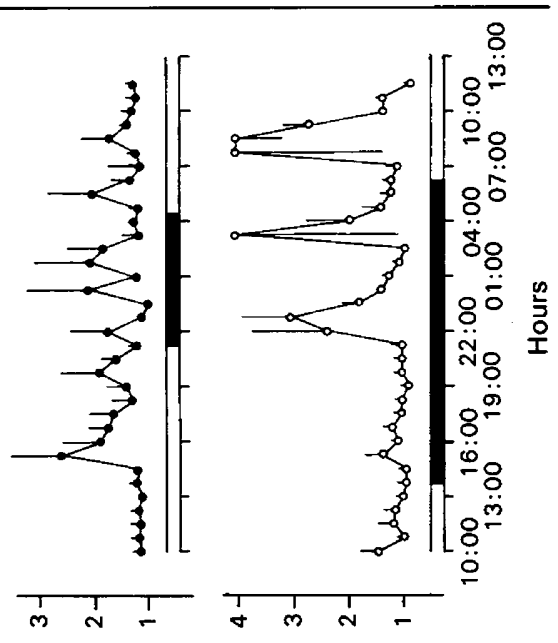

(ןw/6u) Hา

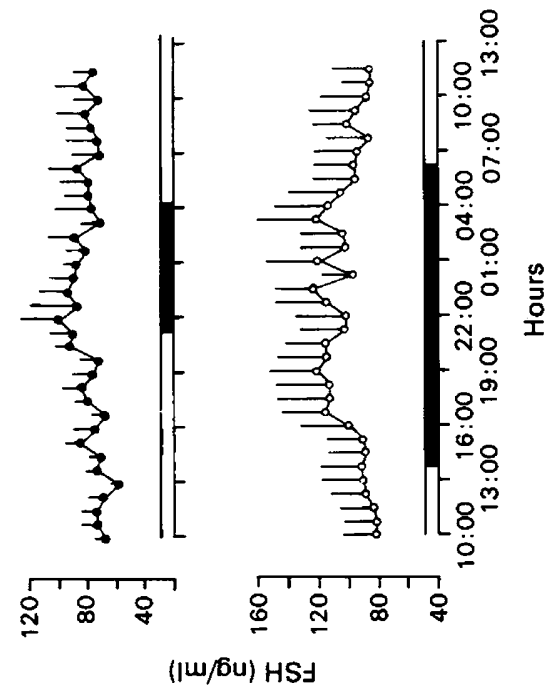




\section{$L H$}

Plasma concentrations of $\mathrm{LH}$ exhibited fluctuations indicative of episodic release in all of the ewes studied. Throughout mid-anoestrus, 1-3 short pulses of LH release were observed per $24 \mathrm{~h}$ in all ewes. The magnitude of these pulses ranged from 3 to 10 times the basal levels of LH when samples were taken every $45 \mathrm{~min}$ (Text-figs $1 \mathrm{a}, 1 \mathrm{~b}$ and $1 \mathrm{c}$ ). The pulses were of short duration ranging from 2.25 to $3.00 \mathrm{~h}$. These data are presented in two ways; as means (Text-fig. 1) and as changes in the frequency of the pulses (Text-fig. $2 \mathrm{~b}$ ).

Pooling the data gave an indication of the degree of synchrony of the pulses during the study period. In mid-anoestrus there was consistent release of LH soon after dawn and another in the middle of the afternoon (Text-figs $1 \mathrm{a}$ and $1 \mathrm{~b}$ ). The early morning surge was also observed in Group $S$ ewes 1 week and 3 weeks after the light treatment was imposed (Text-figs $1 \mathrm{~b}$ and 1c). This synchrony of the pulses was, however, almost totally lost in the ewes in Group $\mathbf{N}$ by 3 weeks after the start of the experiment (Text-fig. 1c). There was no suggestion, however, that more $\mathrm{LH}$ release occurred in the ewes in Group $\mathrm{S}$ than in the ewes in Group $\mathrm{N}$ during this period. There was also no indication that the pulsatile release of $\mathrm{LH}$ was restricted to different phases of light or darkness except for the early morning peak. A second surge of LH was observed in the Group S ewes at the time when it would normally be dusk (Text-figs $1 \mathrm{~b}$ and 1c).

\section{Prolactin}

In all ewes on the first sampling occasion the first plasma samples taken had variable and high levels of prolactin (Text-fig. 1a). This was also observed to a lesser extent on the later occasions. During housing under natural daylength conditions in mid-anoestrus, ewes had high mean levels of prolactin $(15-45 \mathrm{ng} / \mathrm{ml})$ which varied according to the time of day. Plasma concentrations of prolactin were elevated during periods of darkness and into early morning (Text-fig. 1). However, exposure to short days for only 1 week (Group S) almost completely abolished the rise in prolactin that occurred in the dark, and after 3 weeks on short days prolactin concentrations were often undetectable (Text-figs $1 \mathrm{~b}$ and $1 \mathrm{c}$ ).

\section{Changes related to the onset of ovulation}

In an attempt to isolate changes in the concentrations of these hormones that may be related to the onset of ovulation, the data have also been arranged according to the day of first ovulation (Text-fig. 2). Changes in the mean concentrations of FSH were not closely related to the onset of ovulation in any of the ewes (Text-fig. 2a). Some ewes in Group $S$ tended to have higher concentrations of FSH than those in Group $\mathrm{N}$ but this was not a consistent finding.

Ewes in both groups exhibited a similar frequency of LH discharge until approximately 20 days before the first ovulation (Text-fig. $2 \mathrm{~b}$ ). There was a suggestion that the frequency of these pulses was increasing and that the magnitude of each pulse was decreasing as the first ovulation approached. In one ewe the pulses were very frequent and of low magnitude 3 days before the first ovulation, a pattern which is similar to that found on Day 14 of the oestrous cycle (Text-fig. 3).

Plasma concentrations of prolactin were dominated by the effect of the daylength environment and no changes in relation to ovulation were detected (Text-fig. 2c).

Text-fig. 1. Changes in the mean plasma concentrations of FSH, $\mathrm{LH}$ and prolactin in (a) 9 ewes kept in natural daylength on 28-29 June; (b) 4 of the 9 ewes in natural daylength (O) 1 week later and the remaining ewes $(O)$ which had been kept in short days (8L:16D) for 1 week; and (c) the same ewes as in (b) after 3 weeks in natural daylength $(0)$ or short days $(0)$. Vertical bars represent s.e.m. and the timing of the light and dark periods is indicated by the horizontal bars. 


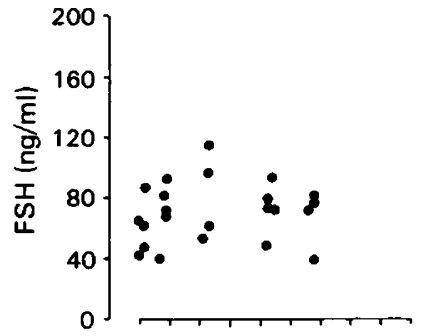

(a)
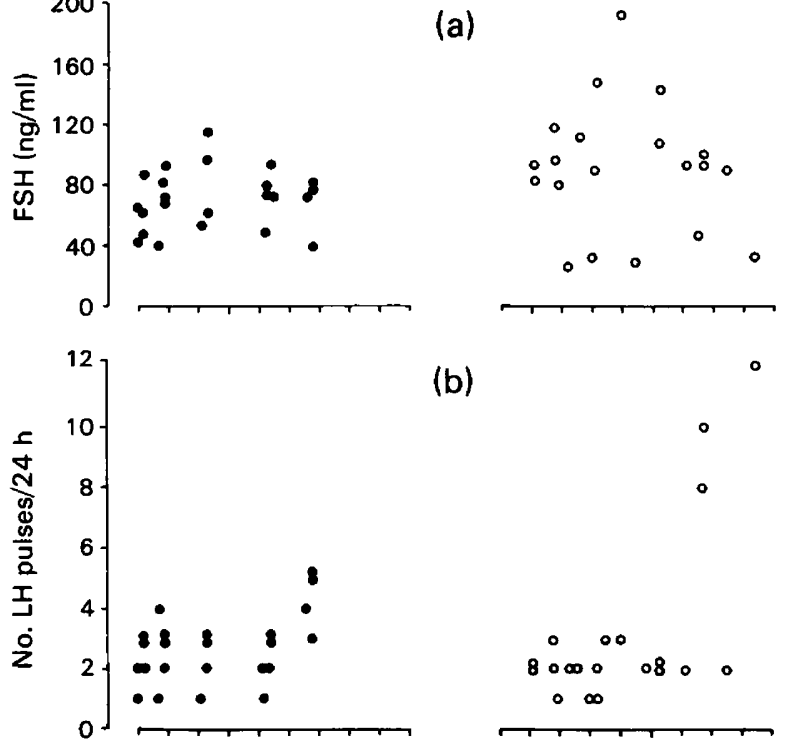

(b)
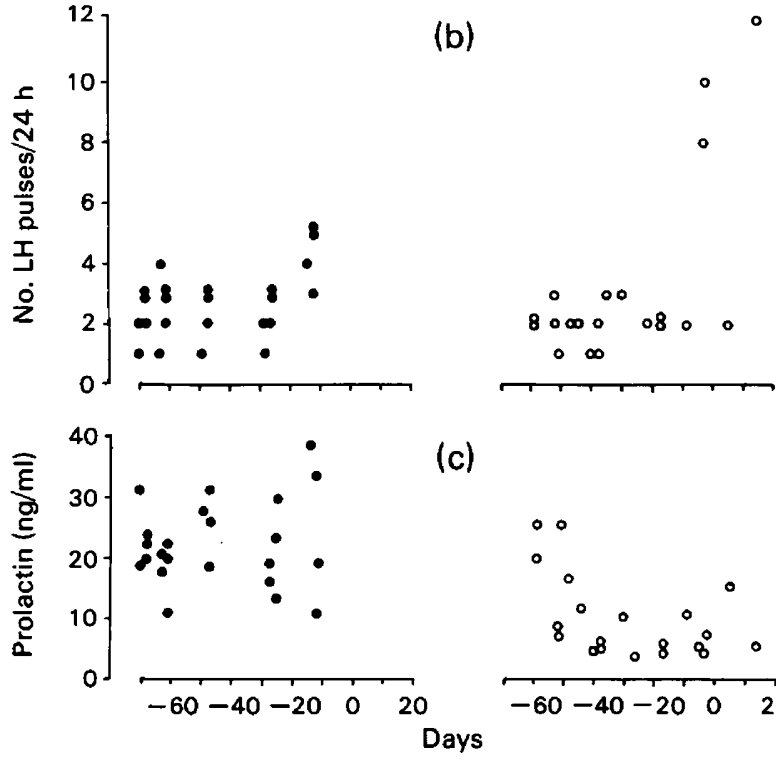

$\circ \infty$

)

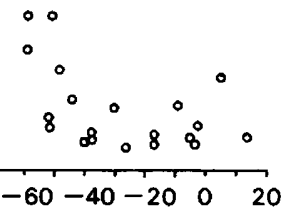

Text-fig. 2. Summary of the hormonal profiles for each 24-h study period in relation to the presumed day of first ovulation (Day 0 ) in ewes kept under natural daylength conditions (O) and short days (8L:16D) (O).
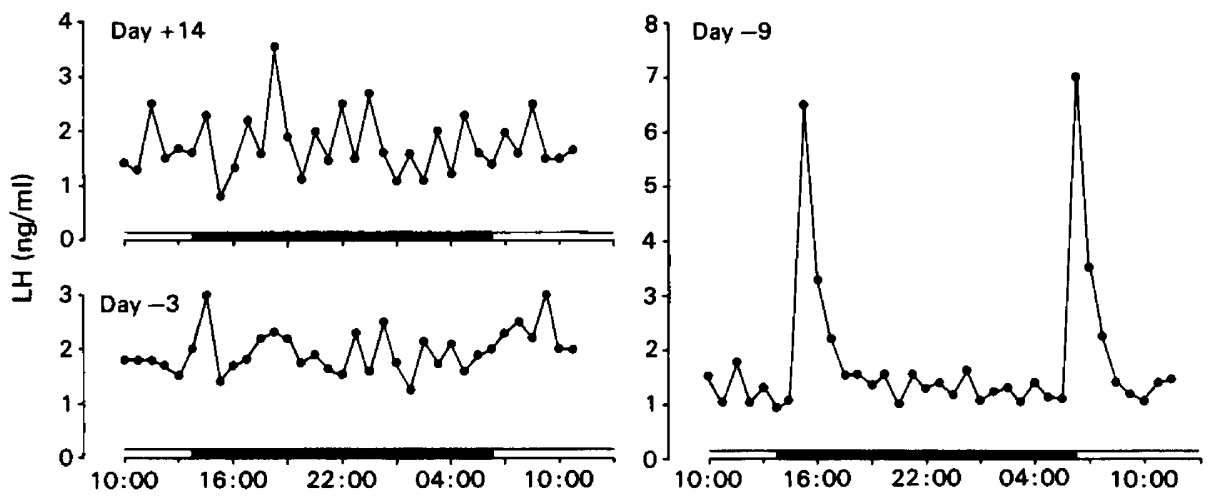

Hours

Text-fig. 3. Plasma concentrations of LH in individual ewes from Group $S$ on Days -9 (Ewe 3 ), -3 (Ewe 4) and +14 (Ewe 6) relative to the presumed day of first ovulation (Day 0). The horizontal bars indicate periods of light and darkness. 


\section{Discussion}

The onset of the breeding season was advanced by subjecting anoestrous ewes to a constant, short photoperiod from the longest day onwards. This is consistent with earlier studies (Ducker et al., 1970; Walton et al., 1977), although a small part of the effect may have been due to the heavier bodyweight of the ewes on short days. There was an unusual degree of synchrony in the onset of oestrus in the ewes kept under natural daylength. However, these ewes, unlike those in Group S, were exposed to a continually changing farm-yard environment, and this synchronization may have been caused by another environmental stimulus, e.g. by inadvertent exposure to strange rams (Hunter \& Lishman, 1967), in addition to the effect of declining daylength.

There was little suggestion that plasma concentrations of FSH fluctuated in accordance with the lighting environment and no changes which could be related either to the lighting treatment or to the onset of ovulation were detected. On occasions, increases in the concentrations of FSH were associated with pulsatile releases of LH but these were of low magnitude and were not consistently observed. The trend towards increasing concentrations of FSH in the early morning during mid-anoestrus is probably associated with the surge of $\mathrm{LH}$ that occurs at this time. These results contrast sharply with the effect of short photoperiods on plasma concentrations of FSH in the ram. A 3 to 4 -fold increase in the concentration of FSH was observed in Soay rams after exposure to short days (8L:16D) for 5 weeks after exposure to long days (16L:8D) (Lincoln \& Peet, 1977). Since these short photoperiods stimulate gonadal function in ewes and rams the mechanisms which control the release of FSH in each sex must be different.

Pulsatile release of LH was observed in all animals on all occasions studied. During the majority of the anovulatory period between 1 and 3 pulses were observed in $24 \mathrm{~h}$. The periodicity and magnitude of these pulses agree with those described by Scaramuzzi \& Baird (1977) when differences between the two experiments in the timing and duration of blood sampling are accounted.for. During mid-anoestrus there was an indication that one of these pulses of LH was closely associated with the end of the dark period and this association was maintained in a large proportion of the animals in both groups during subsequent sampling periods. There was also a suggestion that there was another pulse in the middle of the afternoon and that this was delayed by extending the period of darkness. Apart from changes in the timing of these pulses the data indicated that similar amounts of LH were released in both photoperiods.

There appeared to be an increase in the number of pulsatile releases as the first ovulation approached and just before the first ovulation there were many pulses of low magnitude. This pattern resembles that found during the later stages of the oestrous cycle (Baird, Swanston \& Scaramuzzi, 1976). At approximately 10 days before the first ovulation, therefore, there was an increase in the frequency of pulses and a reduction in the magnitude of each pulse. It is uncertain whether these changes in $\mathrm{LH}$ release are the cause or a reflection of the changing ovarian status.

In addition to these pulsatile fluctations other releases of $\mathrm{LH}$ were observed. One ewe was discarded because a surge of LH of preovulatory proportions was observed on the very first sampling occasion. This was probably induced by the introduction of the rams used to detect oestrus (Hunter \& Lishman, 1967) just before the experiment started. A similar surge was also observed in 1 ewe 5 days before the first ovulation, which was assessed by subsequent changes in the plasma concentrations of progesterone. This supports the view that there are two surges of LH of preovulatory dimensions separated by 5 days before the first normal profile of progesterone secretion after anovulation (Walton et al., 1977).

Plasma concentrations of prolactin were high during mid-anoestrus although not as high as recorded in earlier experiments in which blood samples were taken by venepuncture (Walton $e t$ al., 1977; Thimonier et al., 1978). The release of prolactin observed at the start of the collection period in most of the ewes which had high prolactin levels was probably an initial response to stress (Lamming, Moseley \& McNeilly, 1974), and was much less noticeable in the ewes on 
short daylengths which had low levels of prolactin. In ewes on long days, prolactin levels exhibited a marked diurnal variation: the concentrations increased during the dark period and fell during the beginning of the light period. A similar pattern has also been reported in Soay rams on long days (Lincoln, McNeilly \& Cameron, 1978). This pattern was, however, almost completely abolished by only 1 week on short days and a low level was found in all the ewes kept on short days for the rest of the experiment. These data are consistent with earlier work (Walton et al., 1977; Thimonier et al., 1978) which demonstrated that prolactin levels are reduced in ewes kept in short days.

Exposure to short days, therefore, does not apparently increase the release of FSH or LH in the ewe as has been reported for the ram (Lincoln \& Peet, 1977), at least in the short term. This does not, however, preclude the possibility of daylength controlling gonadotrophin release. This must occur if the hypothesis of the changing hypothalamic sensitivity to oestradiol during the year holds true (Legan et al., 1977). The pulsatile release of gonadotrophin was reasonably well synchronized by the change from darkness to light, suggesting a daylength-mediated hypothalamic control over gonadotrophin release. Although increased hypothalamic activity, as reflected by the frequency of LH release, was observed just before the onset of ovulation, it is uncertain whether this is causing, or is a consequence of, the changing ovarian status. There was, however, no suggestion of a period of increased LH release due to more pulses of increased magnitude, as has been shown in the ewe (Kann et al., 1978) and cow (Lamming, 1978) post partum.

The major effect of decreased daylength was to reduce the circulating concentration of prolactin. This decline was not, however, immediately followed by a return to ovulation. It might be expected that, if inhibition by prolactin was the only factor restraining ovarian activity, then ewes would have responded more quickly to short daylengths than they did. The administration of 2-bromo-a-ergocryptine (CB 154, Sandoz: $2 \mathrm{mg} /$ day) to anoestrous ewes from 14 July to 14 August reduced prolactin concentrations to an undetectable level $(<3 \mathrm{ng} / \mathrm{ml})$ but the onset of oestrus was only marginally advanced (B. P. Fitzgerald, J. S. Walton \& F. J. Cunningham, unpublished observations). It is unlikely, therefore, that the seasonal hyperprolactinaemia per se is solely responsible for anovulation. Nevertheless, part of the response to shortened daylength may involve reducing prolactin levels and so relieve a suppression on the events which normally initiate the new breeding season.

We thank Dr I. T. Kechik for his assistance and the staff of the University farm, Sonning, Berkshire, for care of the animals; Dr S. S. Lynch and Dr B. J. A. Furr for the antisera to human FSH and progesterone; and NIAMDD, NIH, for purified hormones. This study was financed by a grant (A.G. 45/157) from the Agricultural Research Council to F.J.C.

\section{References}

Baird, D.T., Swanston, I. \& Scaramuzzi, R.J. (1976) Pulsatile release of $\mathrm{LH}$ and secretion of ovarian steroids in sheep during the luteal phase of the oestrous cycle. Endocrinology 98, 1490-1496.

Ducker, M.J., Thwaites, C.J. \& Bowman, J.C. (1970) Photoperiodism in the ewe. 2. The effects of various patterns of decreasing daylength on the onset of oestrus in Clun Forest ewes. Anim. Prod. 12, 115-123.

Furr, B.J.A. (1973) Radioimmunoassay of progesterone in peripheral plasma of the domestic fowl in various physiological states and in follicular venous plasma. Acta endocr., Copenh. 73, 663-674.
Goldfine, I.D., Amir, S.M., Petersen, A.W. \& Ingbar, S.H. (1974) Preparation of biologically active ${ }^{125} \mathrm{I}$ TSH. Endocrinology 95, 1228-1233.

Hafez, E.S.E. (1952) Studies on the breeding season and reproduction of the ewe. J. agric. Sci., Camb. 42, 189-265.

Hunter, G.L. \& Lishman, A.W. (1967) Effect of the ram early in the breeding season on the incidence of ovulation and oestrus in sheep. Proc. S. Afr. Soc. Anim. Prod. 6, 199-201.

Kann, G., Martinet, J. \& Schirar, A. (1978) Hypothalamic-pituitary control during lactation in sheep. In Control of Ovulation, pp. 319-333. Eds. D. B. 
Crighton, N. B. Haynes, G. R. Foxcroft \& G. E. Lamming. Butterworths, London.

Lamming, G.E. (1978) Reproduction during lactation. In Control of Ovulation, pp. 335-353. Eds D. B. Crighton, N. B. Haynes, G. R. Foxcroft \& G. E. Lamming. Butterworths, London.

Lamming, G. E., Moseley, S.R. \& MeNeilly, J.R. (1974) Prolactin release in the sheep. J. Reprod. Fert. 40, $151-168$.

Legan, S.J., Karsch, F.J. \& Foster, D.L. (1977) The endocrine control of seasonal reproductive function in the ewe. A marked change in response to the negative feedback action of estradiol on luteinizing hormone secretion. Endocrinology 101, 818-824.

Lincoln, G.A. \& Peet, M.J. (1977) Photoperiodic control of gonadotrophin secretion in the ram: a detailed study of temporal changes in plasma levels of follicle-stimulating hormone, luteinizing hormone and testosterone following an abrupt switch from long to short days. J. Endocr. 74, 355-367.

Lincoln, G.A., McNeilly, A.S. \& Cameron, C.L. (1978) The effects of sudden decrease or increase in daylength on prolactin secretion in the ram. $J$. Reprod. Fert. 52, 305 $\rightarrow 311$.

MacLeod, R.W. (1976) Regulation of prolactin secretion. In Frontiers in Neuroendocrinology, Vol. 4, pp. 169-194. Eds L. Martini \& W. F. Ganong. Raven Press, New York.

MeNeilly, J.R., McNeilly, A.S., Walton, J.S. \& Cunningham, F.J. (1976) Development and application of a heterologous assay for ovine follicle-stimulating hormone. J. Endocr. 70, 69-79.

Radford, H.M., Watson, R.H. \& Wood, G.F. (1960) $A$ crayon and associated harness for the detection of mating under field conditions. Aust. vet. J. 36, $57-66$.

Roche, J.F., Foster, D.L., Karsch, F.J., Cook, B. \& Dziuk, P.J. (1970) Levels of luteinizing hormone in sera and pituitaries of ewes during the estrous cycle and anestrus. Endocrinology 86, 568-572.

Scaramuzzi, R.J. \& Baird, D.T. (1977) Pulsatile release of luteinizing hormone and the secretion of ovarian steroids in sheep during anestrus. Endocrinology 101, 1801-1806.

Thimonier, J., Ravault, J.P. \& Ortavant, R. (1978) Plasma prolactin variations and cyclic ovarian activity in ewes submitted to different light regimens. Annls Biol. anim. Biochim. Biophys. 18, 12291235.

Walton, J.S., McNeilly, J.R., McNeilly, A.S. \& Cunningham, FJ. (1977) Changes in the concentrations of follicle-stimulating hormone, luteinizing hormone, prolactin and progesterone in the plasma of ewes during the transition from anoestrus to breeding activity. J. Endocr. 75, 127-136.

Yuthasastrakosol, P., Palmer, W.M. \& Howland, B.E. (1975) Luteinizing hormone, oestrogen and progesterone levels in peripheral serum of anoestrous ewes as determined by radioimmunoassay. $J$. Reprod. Fert. 43, 57-65.

Received 12 October 1979 